\title{
ArICDE form the archaeal switch complex
}

\author{
Zhengqun Li ${ }^{\mathrm{a}}$, Marta Rodriguez-Franco ${ }^{\mathrm{b}}$, Sonja-Verena Albers ${ }^{\mathrm{a},}$ *, and Tessa E. F. Quax ${ }^{\mathrm{c}, *}$ \\ ${ }^{a}$ Molecular Biology of Archaea, Faculty of Biology, University of Freiburg, Freiburg, Germany \\ ${ }^{b}$ Cell Biology, Faculty of Biology, University of Freiburg, Freiburg, Germany \\ ${ }^{c}$ Archaeal virus-host Interaction, Faculty of Biology, University of Freiburg, Freiburg, Germany
}

* Correspondence should be addressed to Tessa E.F. Quax, tessa.quax@biologie.uni-freiburg.de, or Sonja-Verena Albers, sonja.albers@biologie.uni-freiburg.de, +49761-203-2631

Cells require a sensory system and a motility structure to achieve directed movement. Bacteria and archaea both possess rotating filamentous motility structures that work in concert with the sensory chemotaxis system. This allows microorganisms to move along chemical gradients. The central response regulator protein $\mathrm{CheY}$ can bind to the motor of the motility structure, the flagellum in bacteria and the archaellum in archaea. Both motility structures have a fundamentally different protein composition and structural organization. Yet, both systems receive input from the chemotaxis system. We applied a fluorescent microscopy approach in the model euryarchaeon Haloferax volcanii, and shed light on the sequence order in which signals are transferred from the chemotaxis system to the archaellum. Our findings indicate that the euryarchaeal specific ArICDE are part of the archaellum motor and that they directly receive input from the chemotaxis system via the adaptor protein CheF. Hence, ArICDE are an important feature of the archaellum of euryarchaea, are essential for signal transduction during chemotaxis and represent the archaeal switch complex.

\section{Introduction}

Bacteria and Archaea employ rotating filamentous structures to swim through liquid environments. Although they are functionally similar, there is no structural similarity between the filaments from Bacteria and Archaea (Berg and Anderson, 1973; Alam and Oesterhelt, 1984; Chevance and Hughes, 2008; Jarrell and Albers, 2012; Albers and Jarrell, 2018; Beeby et al., 2020). The archaeal motility structure, the archaellum, has homology to bacterial type IV pili, and it consist of $\sim 10 \mathrm{Arl}$ proteins (previously named Fla proteins) (Kalmokoff and Jarrell, 1991; Jarrell and Albers, 2012; Pohlschroder et al., 2018). The energy required for rotation is derived from ATP hydrolysis (Thomas et al., 2002; Streif et al., 2008; Reindl et al., 2013), and new protein subunits are N-terminally processed and added at the base of the growing filament (Kalmokoff and Jarrell, 1991; Bardy and Jarrell, 2003; Szabo et al., 2006). In contrast, the bacterial motility structure, the flagellum, consists of over 30 different proteins, which are not found in archaea (Chevance and Hughes, 2008; Erhardt et al., 2010; Lassak et al., 2012; Altegoer and Bange, 2015). The energy for flagellum rotation originates from the proton motive force and new protein subunits are added at the tip of the growing filament (Chevance and Hughes, 2008; Erhardt et al., 2010; Altegoer and Bange, 2015).
Despite the fundamental differences in the organization of the archaeal and bacterial motility structures, Archaea and Bacteria both possess the chemotaxis system (Briegel et al., 2015; Quax et al., 2018a). This system allows cells to move along chemical gradients and, in combination with the motility structure, ensures directional movement (Szurmant and Ordal, 2004; Porter et al., 2011; Bi and Sourjik, 2018). Archaea, such as euryarchaea and some thaumarchaea, have likely received the chemotaxis system from bacteria via horizontal gene transfer (Wuichet et al., 2010; Wuichet and Zhulin, 2010; Briegel et al., 2015).

In bacteria the chemotaxis system transfers signals to the base of the flagellum (Sourjik and Berg, 2002; Chevance and Hughes, 2008). Attractants or repellents can bind to chemosensory receptors, methyl-accepting chemotaxis proteins (MCPs), which are often presented at the cell surface (Parkinson et al., 2015; Salah Ud-Din and Roujeinikova, 2017). These MCPs are organized together with $\mathrm{CheW}$ and CheA proteins in chemosensory arrays, which are large organized clusters that ensure signal integration and amplification (Briegel et al., 2012; Briegel et al., 2014). Binding of stimuli to the MCPs triggers a signaling cascade, which eventually leads to phosphorylation of the response regulator protein CheY (Welch et al., 1993; Parkinson 
bioRxiv preprint doi: https://doi.org/10.1101/2020.04.09.033365; this version posted April 9, 2020. The copyright holder for this preprint (which was not certified by peer review) is the author/funder, who has granted bioRxiv a license to display the preprint in perpetuity. It is made available under aCC-BY-NC-ND 4.0 International license.

\section{ArICDE form the archaeal switch complex}

A
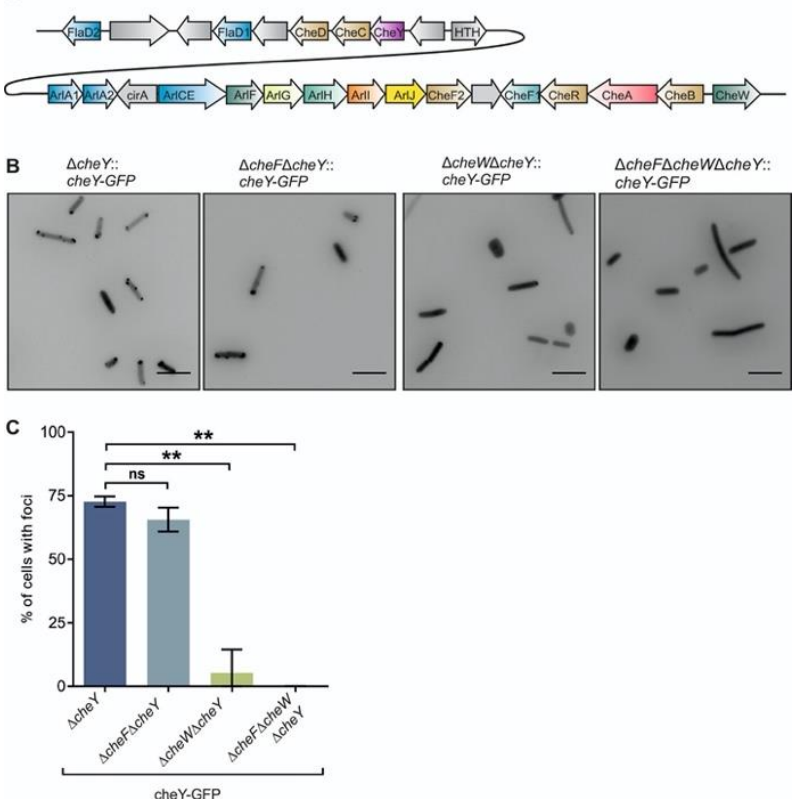

Figure 1 Intracellular positioning of $\mathrm{CheY}$ is mainly dependent on chemosensory arrays in $H$. volcanii. (a) Schematic representation of the archaellum and chemotaxis operon in the model euryarchaeal $H$. volcanii (b) Representative fluorescent micrographs of the intracellular distribution of CheY-GFP clusters in different $H$. volcanii mutants in early stationary phase. I, $\Delta c h e Y$; II, $\Delta c h e F$ $\Delta$ cheY; III, $\Delta$ cheW $\Delta$ cheY; IV, $\Delta$ cheF $\Delta$ cheW $\Delta$ cheY. The number of cells analyzed for each mutant is $n>500$. Scale bars, $5 \mu \mathrm{m}$. (c) Percentages of cells with CheY-GFP foci in the four strains analyzed in A. ${ }^{* *} P<0.01$. ns, not significant $P>0.05$

et al., 2015). Phosphorylated CheY binds with higher affinity to the switch complex at the flagellum motor, which consists of FliM, FliN, and FliG proteins (Barak and Eisenbach, 1992; Sarkar et al., 2010; Paul et al., 2011). This results in a change or a pause in flagellum rotation direction (Sarkar et al., 2010; Paul et al., 2011). These bacterial switch proteins are, like the other flagellum proteins, absent from archaea (Jarrell and Albers, 2012) and the archaeal equivalent of a switch complex has not yet been identified. Therefore, it is still an open question how the archaeal motility structure receives signals from the bacterial-like chemotaxis system.

Recently available cryo-EM structures of the archaellum provide clues to this question. Subtomogram averaging of the archaellum motor of the euryarchaeon Pyrococcus furiosus, revealed a bell-like structure below the motor that stretches into the cytoplasm (Daum et al., 2017). The central core of the motor is formed by the proteins ArlJ, Arll and ArlH (previously named FlaJ, I and $\mathrm{H}$ ) encoded from the archaellum operon (Figure 1a) (Ghosh et al., 2011; Banerjee et al., 2013; Reindl et al., 2013; Chaudhury et al., 2016; Albers and Jarrell, 2018; Chaudhury et al., 2018). ArlJ is an integral membrane protein that was not well resolved in the cryo-Em structure (Daum et al., 2014). Six copies of the cytosolic ATPase Arll and six of the ATP binding protein ArlH, could be mapped into the cytosolic part of the central core of the archaellum (Daum et al., 2017). After mapping I and $\mathrm{H}$, still a large proportion of the cytosolic part of the motor has remained unassigned (Daum et al., 2017). This density has a ring-like shape and was hypothesized to be occupied by ArIC, D and E, because these are the only proteins with unassigned function encoded in eurayarchaeal archaellum operons (Figure 1a). It was suggested that these proteins together form a ring structure, in analogy with the ring structure formed by the crenarchaeal specific protein FlaX protein (Daum et al., 2017; Briegel et al., 2017). In many archaeal genomes, different combinations of fusions of ArIC, D and $E$ are encoded, such as ArICE from the halophilic euryarchaeon Haloferax volcanii, which suggests that the three proteins might form a complex (Albers and Jarrell, 2015). Since the unassigned ring-like density is at the most peripheral part of the motor, it would represent a convenient docking place for chemotaxis proteins. Corresponding with this hypothesis, an interactome study in Halobacterium salinarum, previously indicated that ArICE (fused in this organism) interacts with the archaeal specific chemotaxis protein CheF (Figure 1a) (Schlesner et al., 2009; Schlesner et al., 2012). Motile archaea encoding the bacterial-like chemotaxis system, all possess the adaptor protein CheF, which can bind to CheY and as such forms a link between the chemotaxis system and the archaellum (Schlesner et al., 2009; Quax et al., 2018b).

We aimed to establish in which sequence order chemotaxis proteins transfer signals to the archaellum motor and which motor proteins are likely in direct contact with the chemotaxis system. To address these questions, we used Haloferax volcanii, for which a welldeveloped genetic manipulation system is available, in addition to previously obtained information on the cellular positioning of several chemotaxis and archaellum proteins (Allers et al., 2004; Li et al., 2019). Fluorescent microscopy was employed to study the localization of several proteins, important for signal transduction between the chemotaxis system and the motility machinery. This work sheds light onto the role of the ArIC, D, and E archaellum proteins and indicates that they are a crucial factor in receiving input from the chemotaxis system.

\section{Results}

The chemosensory arrays anchor the archaeal response regulator $\mathrm{CheY}$

We aimed to gain insight into the sequence in which archaeal chemotaxis and archaellum proteins are interacting with each other. First, we focused on the response regulator $\mathrm{CheY}$, which is thought to shuttle between the chemotaxis system and the motility structure (Figure 1a). Previously, we have shown that CheY localizes primarily to the cell poles of motile cells, but it is also present at the lateral membranes ( $\mathrm{Li}$ et al., 
bioRxiv preprint doi: https://doi.org/10.1101/2020.04.09.033365; this version posted April 9, 2020. The copyright holder for this preprint (which was not certified by peer review) is the author/funder, who has granted bioRxiv a license to display the preprint in perpetuity. It is made available under aCC-BY-NC-ND 4.0 International license.

ArICDE form the archaeal switch complex

A

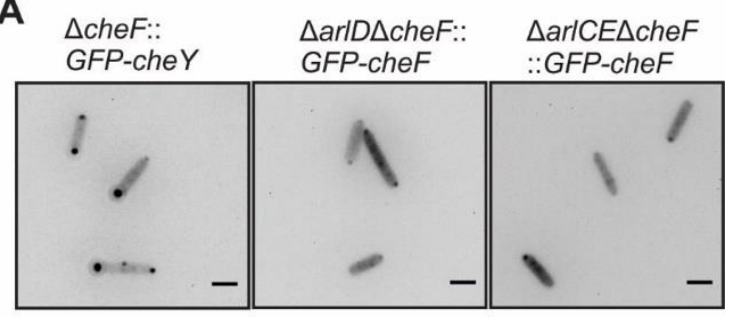

B

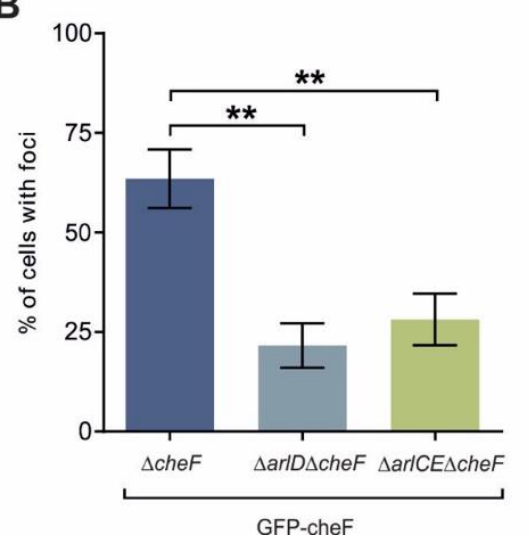

Figure 2 The archaellum proteins ArID and ArICE are important for communication with the chemotaxis system. (a) Representative fluorescent images of the intracellular distribution of GFP-CheF clusters in different $H$. volcanii mutants in exponential phase Scale bars, $2 \mu \mathrm{m}$. (b) Percentages of cells with GFP-CheF clusters in the strains described in (a). The number of cells of each mutant analyzed is $n>500$. ${ }^{* *} P<0.01$ as established by T-test.

2019). This positioning pattern shares similarities with that of the chemosensory arrays and with that of archaella, which are exclusively present at cell poles (Li et al., 2019). As CheY was shown to interact with the archaeal specific chemotaxis protein CheF (Schlesner et al., 2009; Quax et al., 2018b), we wondered if it might position at the archaellum motor in a CheF dependent manner. A $H$. volcanii $\Delta$ che $Y \Delta c h e F$ mutant was constructed in which either CheY-GFP or GFP-CheF were expressed. These fusion proteins were shown to be correctly expressed by Western blot analysis and were previously shown to restore motility on semi-solid agar plates (Figure S1a. Table S1) (Li et al., 2019). The positioning pattern of GFP-CheY did not significantly differ in the $\Delta c h e Y \Delta c h e F$ and in the $\Delta c h e Y$ strain (Figure 1b,c). In both cases, polar and lateral foci were observed, suggesting that localization of the response regulator CheY is mainly independent of CheF (Figure 1b, c).

Next, we tested if CheY might bind to chemosensory arrays. CheW was previously used as a marker protein to indicate the cellular position of chemosensory arrays in H. volcanii (Li et al., 2019). A $\Delta$ cheY $\Delta$ cheW deletion strain was created in which CheY-GFP was expressed. Observation of this strain by fluorescent microscopy showed that cells mostly displayed a diffuse fluorescent signal in the cytoplasm, with the exception of a few polar foci in a low number of cells $(5.3 \%)$ (Figure 1b, c). When GFP-CheY was expressed in a $\Delta c h e Y \Delta c h e F \Delta c h e W$ strain, also the residual signal at the cell poles disappeared and the fluorescent signal was exclusively diffuse (Figure 1b, c). These findings indicate that in exponentially growing cells, CheY is mainly bound to chemosensory arrays, while a very small fraction might be present at the archaellum motor via binding to CheF.

\section{ArID and ArICE are important for communication} with the chemotaxis system

CheF was previously shown to position mainly at the cell poles of $H$. volcanii (Li et al., 2019). Therefore, we asked if CheF could be permanently localized at the archaellum motor in motile cells. The proteins ArID and ArICE both are encoded in the archaellum operon in euryarchaea and have an unknown function (Figure 1a) (Albers and Jarrell, 2015; Albers and Jarrell, 2018). They are hypothesized to be part of the archaellum motor (Daum et al., 2017; Briegel et al., 2017) and preliminary data from $M$. maripaludis suggest that they are membrane associated, although they both lack a transmembrane domain (Thomas and Jarrell, 2001; Thomas et al., 2002). As an interactome study suggested that ArICE might be in direct contact with the archaeal specific chemotaxis protein CheF (Schlesner et al., 2009), we asked if CheF requires ArICE and ArID to bind to the archaellum motor. As $\mathrm{H}$. volcanii encodes two ArID homologs, we made knock-outs of both genes. arID2 is encoded from a gene a little upstream of the archaellum operon (Figure 1a). Analysis of a $\triangle a r l D 2$ strain on semi-solid agar plate, showed that directional movement and motility were comparable to the wild type (Figure S2a, b). In contrast, $\triangle$ arlD1 has a severe motility defect, as the archaellum is not correctly produced anymore (Li et al., 2019). Therefore, we continued with ArID1 and refer to this protein as ArID, throughout the paper. Next, we constructed the $\triangle a r I D$ $\triangle c h e F$ and $\triangle a r l C E \triangle c h e F$ deletion strains in $H$. volcanii. GFP-CheF was expressed in $\triangle a r l D \triangle c h e F$ and $\triangle a r l C E$ $\Delta c h e F$. Interestingly, the positioning pattern of GFPCheF showed significant difference in both a $\triangle a r I D$ $\triangle c h e F$ and a $\triangle a r l C E \triangle c h e F$ strain compared to that in a $\Delta$ cheF strain (Figure 2a, b). GFP-CheF foci were observed at the cell poles in $65 \%$ of $\Delta$ cheF cells, consistent with what has been described previously (Table S1) (Li et al., 2019). In contrast, the number of cells with polar GFP-CheF foci was significantly reduced in both the $\triangle a r l D \triangle c h e F$ and the $\triangle a r l C E$ $\Delta$ cheF strain (to $\sim 20 \%$ of cells) (Figure $2 a, b)$. These findings indicate that ArID and ArICE promote, but are not essential for, CheF positioning to the cell pole. It might be possible that the largest fraction of CheF proteins is positioned at the cell pole via interaction with ArICE and ArID that are bound to the archaellum motor. A smaller fraction of CheF might be positioned at the cell pole because of other protein interactions.

Polar positioning of ArID and ArICE is interdependent 
bioRxiv preprint doi: https://doi.org/10.1101/2020.04.09.033365; this version posted April 9, 2020. The copyright holder for this preprint (which was not certified by peer review) is the author/funder, who has granted bioRxiv a license to display the preprint in perpetuity. It is made available under aCC-BY-NC-ND 4.0 International license.

ArICDE form the archaeal switch complex

A

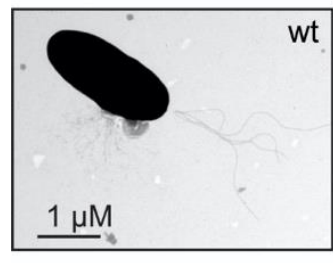

B
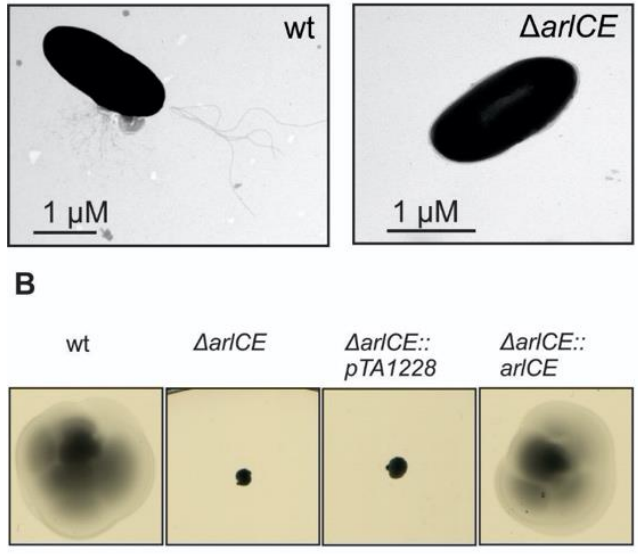

C

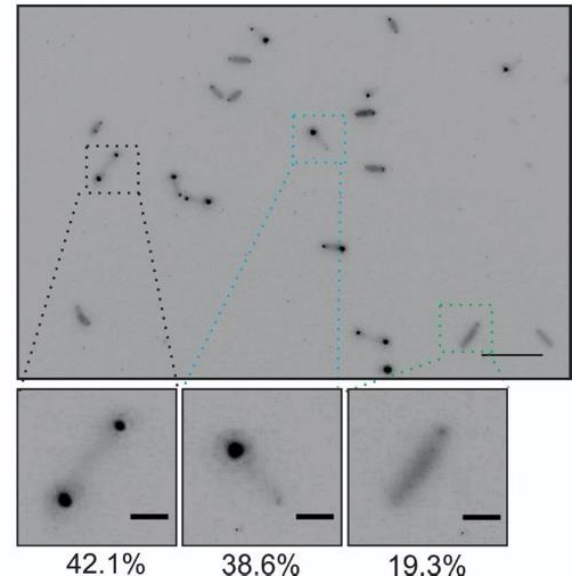

Figure 3 The positioning pattern of ArICE is reminiscent of that of ArID. (a) Transmission electron microscopy (TEM) of the wild-type (WT) and $\triangle$ arlCE H. volcanii cells. Scale bar, $1 \mu \mathrm{m}$. (b) Influence of ArICE on directional movement. Representative image of motility assay of different $H$. volcanii strains on semis solid agar plates. This experiment was performed on at least 3 independent occasions. pTA1228, empty plasmid (c) Representative fluorescent image of ArICE-GFP clusters in H.volcanii $\triangle a r l C E$ cells in early exponential phase. The percentages of cells with each positioning pattern are showed below the corresponding exemplary images. The total population of the analyzed cells was $n>500$. Scale bars, $10 \mu \mathrm{m}$ (upper panel) and 2 $\mu \mathrm{m}$ (lower panels).

After we demonstrated the importance of ArID and ArICE for positioning of the chemotaxis adaptor protein CheF, we aimed to gain more information on the possible function of these two proteins. Previously we have shown that ArID is likely part of the archaellum motor, as fluorescent fusion proteins of ArID were positioned at the cell poles of rod-shaped motile $H$. volcanii cells, the location where also archaella are found (Table S1) (Li et al., 2019). In order to test if the ArICE protein is also part of the archaellum motor, we constructed a $\triangle$ arlCE deletion strain. Analysis by EM showed that this strain does not have archaella at its surface (Figure 3a), and did not form motility rings on semi-solid agar plate (Figure $3 \mathrm{~b}$ ). We expressed Nand C-terminal GFP fusions of ArlCE in a $\triangle$ arlCE strain. While expression of native ArICE could restore the motile phenotype on semi-solid agar plate (Figure 3b), both GFP fusions did not restore motility (Table S1). Western blot analysis with a-GFP antibodies did not show a clear signal for either fusion, indicating that expression of ArICE fusions to GFP yielded only low levels of the fusion proteins (data not shown). Correspondingly, $\triangle$ arlCE strains expressing GFPArICE or ArlCE-GFP observed by fluorescence microscopy, had only a very low total GFP signal. Still, distinct foci were observed, exclusively near the cell poles of the motile rod-shaped cells (Figure 3c). 39\% of the cells showed an ArICE-GFP signal at one pole, while $42 \%$ showed bipolar ArlCE-GFP foci. The percentages were similar for the GFP-ArICE signals. This positioning pattern is reminiscent of that of ArID, suggesting that ArICE also positions at the archaellum motor (Li et al., 2019).

To confirm this hypothesis, ArID-GFP and ArICEmCherry were co-expressed in a $\triangle a r l D \triangle a r l C E$ strain. The signals of both proteins overlapped, suggesting
ArID and ArICE co-localized (Figure 4a). To study if the positioning of the two proteins was interdependent, ArID-GFP or ArICE-GFP were expressed in the $\triangle a r I C E$ $\triangle a r I D$ strain. Western blot analysis showed that ArIDGFP was correctly expressed in this background (Figure S1c). Comparison with the positioning pattern of the two proteins in the control strains, showed that the number of cells with distinct ArID or ArICE foci, was significantly reduced in absence of either of the other protein (Figure 4b, S2c). Thus, the correct positioning of ArID or ArICE at the archaellum motor is dependent on the presence of both proteins. This suggests that ArID and ArICE might form a precomplex, required for binding to the archaellum motor.

ArID and ArICE promote positioning of CheF at the cell pole (Figure 2). To test if ArID and ArICE also require CheF for polar localization, we expressed ArID-GFP and ArICE-GFP in a $\triangle a r l D \Delta c h e F$ strain and in a $\triangle$ arlCE $\triangle$ cheF strain, respectively. We compared the number of cells with polar foci in these strains with those of the $\triangle$ arlD ArID-GFP and the $\triangle a r l C E$ ArICEGFP strain. The positioning pattern of ArID and ArICE was not significantly affected in the absence CheF (Figure S3). Thus, ArID and ArICE do not require CheF for correct positioning at the cell pole.

\section{ArID and ArICE dock on the archaellum motor via} binding to ArlH

As we demonstrated that CheF is not responsible for polar positioning of ArICE and ArID, we hypothesized that the ArICE and ArID proteins are likely localized at the cell pole by direct binding to the archaellum motor. The core of the motor consists of $\mathrm{ArlH}$, Arll and the membrane protein ArlJ, which interact with each other to form a large oligomeric complex (Banerjee et al., 
bioRxiv preprint doi: https://doi.org/10.1101/2020.04.09.033365; this version posted April 9, 2020. The copyright holder for this preprint (which was not certified by peer review) is the author/funder, who has granted bioRxiv a license to display the preprint in perpetuity. It is made available under aCC-BY-NC-ND 4.0 International license.

\section{ArICDE form the archaeal switch complex}

A
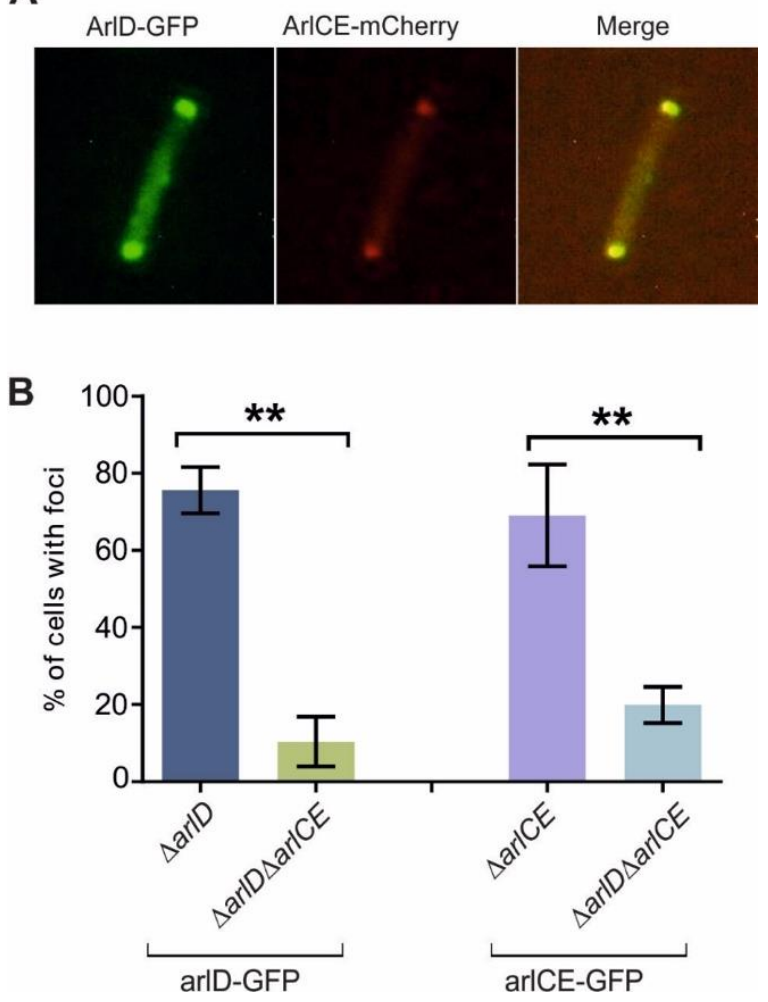

Figure 4 The positioning of ArID and ArICE are dependent on each other in H.volcanii. (a) Co-expression of ArID-GFP and ArlCE-mCherry in the H.volcanii $\triangle a r I D$ $\triangle$ arlCE strain in early exponential phase. (b) Percentages of cells with intracellular ArID or ArICE foci in single and double knockout strains. $\mathrm{N}>500 .{ }^{* \star} P<0.01$ as established by T-test.

2013; Reindl et al., 2013; Chaudhury et al., 2016). The cryo-EM structure of the archaellum motor of euryarchaea was resolved previously, which indicated that $\mathrm{ArlH}$ interacts with a ring like density that might consist of ArIC, D and E (Daum et al., 2017). Therefore, we first tested if ArID and ArICE might require ArlH for polar localization. First, a $\Delta$ arl $H$ strain was constructed in $H$. volcanii. Analysis on semi-solid agar plate showed that the $\Delta$ arl $H$ strain did not form motility rings, in correspondence with the fact that a mutant in other archaea, was previously shown to possess no archaella (Chaban et al., 2007; Staudinger, 2008; Chaudhury et al., 2016) (Figure 5a). Expression of native $\mathrm{ArlH}$ in the $\mathrm{ArlH}$ strain could complement the ability of motility on semi-solid agar plate (Figure $5 \mathrm{a}$ ). In contrast, expression of an ArlH-GFP fusion did not restore motility (Table S1). However, Western blot analysis indicated that the fusion protein ArlH-GFP was correctly expressed (Figure S1b) and expression of ArlH-GFP in the $\triangle \mathrm{arlH}$ strain resulted in foci at the cell pole in the majority of cells (64\%), corresponding with fact that ArlH is part of the archaellum motor (Figure 5b). Possibly, fusion of GFP to the C-terminus of ArlH, blocks interaction with other proteins or hinders its function, thus rendering this mutant non-motile.
Western blot analysis of the GFP-arlH fusion protein showed two bands, in size corresponding to $\mathrm{ArlH}$ and to GFP (Figure S1b). Thus, the GFP-ArlH fusion protein was likely cleaved. Fluorescence microscopy analysis suggested that this is indeed the case, as GFP-ArlH expression in a $\Delta a r l H$ resulted in a diffuse GFP signal in the cytoplasm (Figure 5b). GFP-ArlH could restore the motility of a $\Delta$ arlH strain on semi-solid agar plate, which is likely the result of incorporation of the cleaved ArlH, without GFP tag (Figure 5a), in the archaellum motor.

Next, the double deletion strains $\triangle a r I D \triangle a r l H$ and $\triangle$ arlCE $\triangle$ arlH were constructed to test the influence of $\mathrm{ArlH}$ on ArID and ArICE positioning. The number of cells with polar foci was reduced significantly in the $\triangle a r l D \Delta$ arlH strain expressing ArID-GFP (27\%), in comparison with expression of this construct in the $\triangle$ arlD strain (69\%)(Figure 5c, d). ArID-GFP was correctly expressed in this background as observed by Western blot analysis (Figure S1c). A similar observation was made for ArlCE-GFP expression in the $\triangle \mathrm{arlCE} \triangle \mathrm{arlH}$ strain, where a reduction of $\sim 70 \%$ to $\sim 36 \%$ of cells with polar foci was detected (Figure S4a, b). As the polar positioning of both ArID and ArICE was severely diminished in absence of $\mathrm{ArlH}$ (Figure $5 \mathrm{c}, \mathrm{d}$, S4a, b), ArID and ArICE likely dock to the archaellum motor via ArlH. However, $30 \%$ of cells still form ArIDGFP or ArICE-GFP foci at the cell pole in the $\Delta$ arlH strains (Figures 5c, d, S4a, b), which indicates that ArID and ArICE can also position themselves at the cell pole by another mechanism. To test if the remainder of polar localization of ArID and ArICE, might be caused by interaction with other archaellum motor proteins, we created knock outs of Arll and ArlJ in H. volcanii. Arll is in direct interaction with ArlH, while ArlJ a membrane protein to which Arll is bound (Banerjee et al., 2013; Chaudhury et al., 2016). For this reason, ArlH is not expected to bind to the archaellum motor in absence of either Arll or ArlJ. Analysis on motility plate showed that the $\Delta$ arll strain and the $\Delta$ arlJ strain did not form motility rings (Fig S4C), which corresponds to the previously reported absence of archaella in similar knock-out strains in other archaea (Patenge et al., 2001; Thomas et al., 2002; Chaban et al., 2007). Expression of GFPArll in $\Delta$ arll could restore the motile phenotype on semisolid agar plates (Table S1) (Figure S4c). Arll-GFP expression did not restore motility (Table S1). Expression of both fusion proteins was extremely low and could not be detected by Western blot analysis, while fluorescence microscopy showed a faint signal at the cell poles when GFP-Arll was expressed in a $\Delta$ arll background (Fig S4d).

Expression of ArID-GFP in $\triangle a r I D \Delta$ arll, resulted in a reduction of the percentage of cells with polar foci $(\sim 28 \%)$ compared to the expression of the same construct in the $\triangle a r I D$ strain $(\sim 70 \%)$ (Figure $5 \mathrm{c}$ ). Similarly, when arlJ was deleted, $27 \%$ of cells kept polar ArID-GFP foci. Thus, after deletion of either $\mathrm{arlH}$, arll and arlJ the number of cells with polar ArID foci is strongly reduced but does not drop below $25 \%$. Similar 
bioRxiv preprint doi: https://doi.org/10.1101/2020.04.09.033365; this version posted April 9, 2020. The copyright holder for this preprint (which was not certified by peer review) is the author/funder, who has granted bioRxiv a license to display the preprint in perpetuity. It is made available under aCC-BY-NC-ND 4.0 International license.

\section{ArICDE form the archaeal switch complex}

A

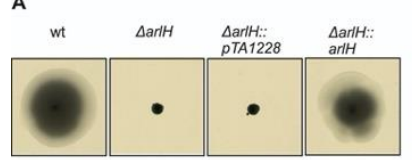

B
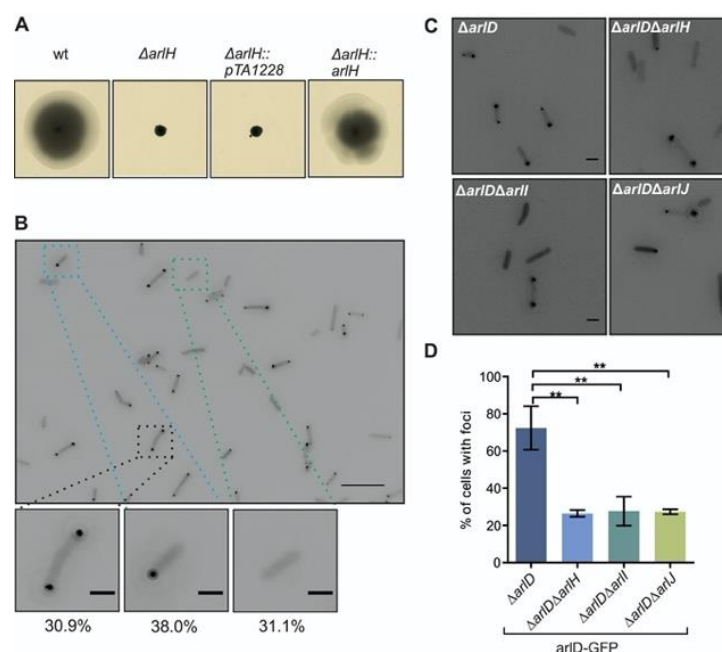

Figure 5 Polar localization of ArID is mainly determined by binding to the archaellum motor (a) Influence of $\mathrm{ArlH}$ on directional movement. Motility assay on semi-solid agar plate of different $H$. volcanii strains in rich medium. pTA1228, empty plasmid (b) Intracellular distribution of GFP-ArlH clusters in the $H$. volcanii $\Delta$ arlH strain. The percentage of total cells with each pattern are showed at the bottom. $n>$ 500. Scale bars, $10 \mu \mathrm{m}$ (upper panel) and $2 \mu \mathrm{m}$ (lower panels). (c) Representative fluorescent images of intracellular distribution of ArID-GFP $H$. volcanii strains in which different archaellum motor proteins were deleted.

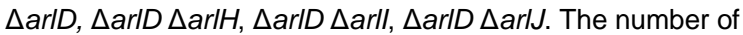
each analyzed mutant, $n>500$. Scale bars, $2 \mu \mathrm{m}$. (d) Percentages of cells with intracellular ArID-GFP foci in strains described in (c). ${ }^{* *} p<0.01$ as established by T-test.

expression levels of ArID-GFP were detected in all strains by Western blot analysis (Fig S1C). Comparable results were obtained for an ArICE-GFP construct in a $\triangle a r l C E \triangle a r l H$, a $\triangle a r l C E \triangle a r l l$ and a $\triangle$ arlCE $\triangle$ arlJ strain (Figure S4a, b). This suggests that positioning of ArID and ArICE at the cell poles, relies mainly on binding of these proteins to $\mathrm{ArlH}$. However, a smaller population of ArID and ArICE proteins might also associate with other polar factors.

\section{Dynamics of ArICE and ArID}

ArID foci are dynamic in vivo and were previously shown to display mobility in the polar region of the cell (Li et al., 2019) (Movie S1, Figure 6a). ArID movement is mainly restricted to the cell pole, and occasionally also movement from particular small ArID foci was observed from one cell pole to another (Li et al., 2019). As our above described findings suggested that ArICE and ArID might form a precomplex required for interaction with the archaellum motor, we first made fluorescent time-lapse movies of ArICE-GFP expressed in a $H$. volcanii $\triangle a r l C E$ strain. Dynamic behavior of ArICE was observed, specifically restricted to the cell pole. This movement of ArICE was largely similar to the behavior of ArID (Figure 6b, Movie S2). We assumed that this highly dynamic ArID and ArICE foci represent a part of the population that is not bound to the archaellum motor. To test this hypothesis, we studied the localization of the archaellum motor by time lapse microscopy of a $\Delta \mathrm{arlH}$ strain expressing $\mathrm{ArlH}$ GFP. ArlH foci remained localized at the cell pole over the course of an hour, suggesting that the archaellum motor is stably positioned at the cell pole (Movie S3, Figure $6 \mathrm{c}$ ). This behavior is different from that of the dynamic behavior of ArID and ArICE. Together with the above described data, this suggests that ArICE and ArID likely form a complex, and that these complexes are localized at one or both cell poles. As the majority of the ArICE and ArID population is bound to the archaellum motor via $\mathrm{ArlH}$, it is likely that specifically the unbound ArICE and ArID populations display the dynamics in the polar region.

\section{Discussion}

The motility structures of bacteria and archaea have a fundamentally different structural organization. Yet, both receive input from the chemotaxis system. This system allows cells to direct their movement along chemical gradients in order to find optimal conditions for survival. In bacteria, the central response regulator CheY binds to proteins at the base of the flagellum motor, the 'switch complex'. As archaea lack homologs of the switch complex, we searched for archaellum motor proteins receiving signals from the chemotaxis system. Previously it has been shown that the archaeal specific adaptor protein $\mathrm{CheF}$ is required for functional chemotaxis in archaea. This protein can bind to archaeal CheY. However, the sequence order in which chemotactic signals are transferred via CheY and CheF to the archaeal motility machinery was until now unresolved. Our findings suggest that the archaellum proteins ArICE and ArID are the direct receivers of signals from the chemotaxis system and represent the archaeal equivalent of the 'switch complex'.

By studying the localization of CheY-GFP fusions in different knock-out mutants, we could determine that in $H$. volcanii, CheY is primarily bound to the chemosensory arrays. This resembles the situation in E.coli where also the large majority of CheY proteins is present at the chemosensory arrays (Thiem et al.,
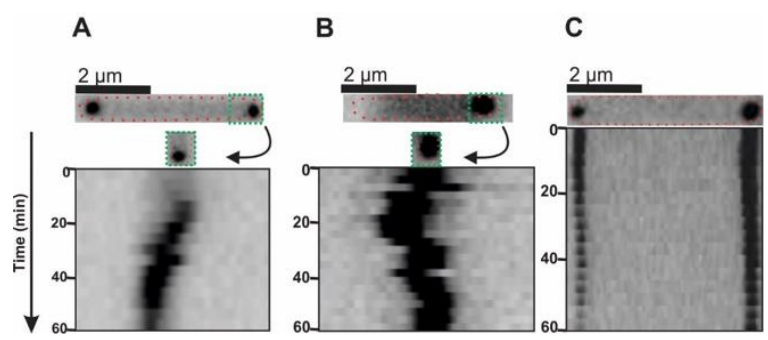

Figure 6 Intracellular dynamics of archaellum proteins ArICE, ArID and ArIH. Time-lapse images of (a) $\triangle a r I D$ :: ArID-GFP (b), $\triangle$ arlCE ::ArICE-GFP (c) and $\triangle$ arlH GFP-ArlH . The upper panel shows a fluorescent image of the selected cells in which GFP-fused proteins were followed during 60 min. The lower panel displays kymographs of the cells shown on top. Cells are representable for $>20$ analyzed cells per strain. See also Movie S1, S2 and S3. 
bioRxiv preprint doi: https://doi.org/10.1101/2020.04.09.033365; this version posted April 9, 2020. The copyright holder for this preprint (which was not certified by peer review) is the author/funder, who has granted bioRxiv a license to display the preprint in perpetuity. It is made available under aCC-BY-NC-ND 4.0 International license.

ArICDE form the archaeal switch complex

2007). In contrast, the polar positioning of CheF indicated that the largest fraction of this chemotaxis protein is normally bound to the archaellum motor.

Binding of CheF to the archaellum motor depends on the presence of both ArICE and ArID. Expression of fluorescent fusion proteins showed that ArICE and ArID co-localize and might form a complex. We suggest that the proteins form a precomplex, which is required for their binding to the archaellum motor. A strong interaction between these proteins would be in line with the fact that the $a r l C, D$ and $E$ genes in different combinations are often fused in archaellum operons of different euryarchaea (Chaban et al., 2007; Jarrell and Albers, 2012). In addition, a dependency of these proteins on each other would fit well with the hypothesizes that the ArIC, D and E proteins make up the unassigned density at the base of the archaellum motor in cryo-EM structures of euryarchaea (Daum et al., 2017; Briegel et al., 2017).

We found that the localization of both ArICE and D depends on the archaellum motor protein ArlH (Figure 7). Also this is in line with the hypothesis that ArICDE make up the ring like structure at the cytoplasmic side of the archaellum motor, since this part is in direct contact with the density in which the ArlH crystal structure could be mapped (Daum et al., 2017).

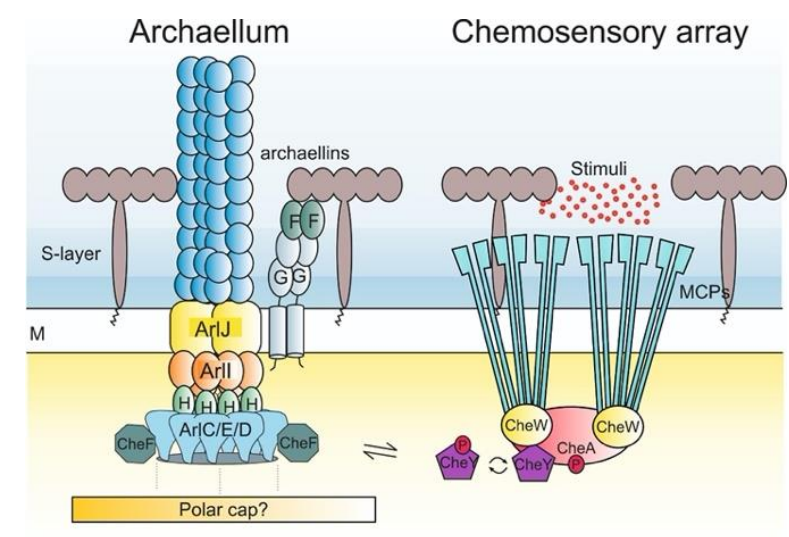

Figure 7 Simplified model of the chemotaxis signal transduction system and the archaellum in euryarchaea. MCPs are organized in chemosensory arrays together with CheW and CheA, which is necessary for signal integration and amplification. Autophosphorylation of CheA, results in phosphorylation of CheY. Phosphorylated CheY binds CheF, which is present at the base of the archaellum motor. CheF requires ArICDE that form the switch complex, for binding to the archaellum motor. Possibly ArICDE are not only binding to the archaellum motor protein $\mathrm{ArlH}$, but are also interacting with the polar cap, to ensure polar localization. Chemotaxis accessory proteins are left out for simplicity. Blue, extracellular environment. Yellow, cytoplasm. M, membrane. MCP, methyl-accepting chemotaxis protein. Red dots, environmental stimuli that bind to the MCPs.
Surprisingly a small fraction of the ArICE and ArID proteins could still localize at the cell poles, even in absence of the archaellum motor (such as when ArlH, Arll or ArlJ are deleted). Thus, ArICE and ArID are likely also capable of binding to other polar factors for their positioning. One candidate for this might be the 'polar cap' or 'cytoplasmic cone', which was revealed by whole-cell cryo-tomography of $P$. furiosus and $T$. kodakaraensis at a defined distance below the archaella motors and the cell membrane (Daum et al., 2017; Briegel et al., 2017). The polar cap is likely a typical feature of motile euryarchaeal cells (Kupper et al., 1994; Daum et al., 2017; Briegel et al., 2017). The polar cap is in close proximity to the archaellum motor, but a direct connection was not observed (Daum et al., 2017; Briegel et al., 2017). The protein constitution of this polar cap is not known. It might be possible that ArICE and ArID can interact with the unknown polar cap protein(s) and as such are polar localized even in the absence of the archaellum. Precomplex formation might not be required for interaction with a pole organizing factor, as polar localization of GFP fused ArID or ArICE was still observed for a fraction of the cells, even when both $a r I D$ and $\operatorname{arlCE}$ were deleted. This is in contrast to binding of ArID and ArICE to the archaellum motor, which is strongly affected by the absence of either one of the proteins.

In summary, our findings suggest a central role for the ArICE and ArID proteins in the signal transduction from the chemotaxis system to the archaellum machinery. Extracellular stimuli are received by chemosensory receptors, organized in chemosensory arrays. Stimuli lead, via CheW, to autophosporylation of CheA and phosphorylation of CheY (Figure 7). Phosphorylated CheY then interacts with the archaeal specific chemotaxis protein CheF. CheF requires ArICE and ArID to bind to the archaellum motor. ArICE and ArID in their turn rely on interaction with the central motor protein ArlH (Figure 7). Possibly, a small proportion of the ArICE and ArID proteins also interacts with a polar organizing factor, such as the polar cap (Figure 7).

Thus, for a functional interaction between the bacteriallike chemotaxis system and the archaeal motility machinery, two important features are required in those archaea possessing both systems: i) the adaptor protein CheF and ii) ArICDE that allow CheF binding to the archaellum motor. This work suggests that ArICDE directly receive input from the chemotaxis system and might represent the archaeal equivalent of the switch complex. The hypothesis that they are conveniently located in the bell-like structure below the euryarchaeal archaellum motor, awaits further structural characterization of these three proteins.

\section{Experimental procedures}

Growth and genetic manipulation of $H$. volcanii. $H$. volcanii strains were cultured as previously described (Quax et al., 2018b; Li et al., 2019). Genetic manipulation and gene expression based on selection 
bioRxiv preprint doi: https://doi.org/10.1101/2020.04.09.033365; this version posted April 9, 2020. The copyright holder for this preprint (which was not certified by peer review) is the author/funder, who has granted bioRxiv a license to display the preprint in perpetuity. It is made available under aCC-BY-NC-ND 4.0 International license.

ArICDE form the archaeal switch complex

with uracil in $\triangle$ pyrE2 strains were performed with PEG 600 as described previously (Allers et al., 2004). The cells were cultured shaking at $120 \mathrm{rpm}$ at $45^{\circ} \mathrm{C}$ or $42{ }^{\circ} \mathrm{C}$ in complete YPC medium containing $5 \%$ Bacto ${ }^{\mathrm{TM}}$ yeast extract, $1 \%$ peptone (Oxoid, UK), 1\% BactoTM Casamino acids (BD Biosciences, UK) or in selective CA medium containing only $5 \%$ BactoTM casamino acids in $18 \%$ SW (Salt water, containing per liter 144 $\mathrm{g} \mathrm{NaCl}, 21 \mathrm{~g} \mathrm{MgSO}_{4} \times 7 \mathrm{H}_{2} \mathrm{O}, 18 \mathrm{~g} \mathrm{MgCl}_{2} \times 6 \mathrm{H}_{2} \mathrm{O}, 4.2$ $\mathrm{g} \mathrm{KCl}$, and $12 \mathrm{mM}$ Tris $\mathrm{HCl}, \mathrm{pH}$ 7.3). Plasmids based on pTA1228 (Brendel et al., 2014), with pyrE2 for selection with uracil, were constructed to express proteins in $H$. volcanii strains (Table S3). Plasmids based on pTA131 were used to create knock-out constructs for the pop-in pop-out method based on the pyrE2 gene. Salt stable GFP and mCherry genes were introduced to pTA1228 plasmid, allowing expression of $\mathrm{N}$-terminal and $\mathrm{C}$-terminal fluorescent fusion proteins in H. volcanii strains (Duggin et al, Nature, 2015).

Deletions of genes in $H$. volcanii strains. The primers used to create knockout plasmids based on pTA131 are described in Table S2. Construction and transformation of knock-out plasmids was performed as described previously (Allers et al., 2004). Selection for pop-in occurred on CA plates. This was followed by 3 transfers in liquid YPC medium. Then the inoculum was diluted $10^{-3}$ and cultured on CA plates with 50 $\mu \mathrm{g} / \mathrm{mL} 5$-FOA and $10 \mu \mathrm{g} / \mathrm{mL}$ uracil for the pop-out selection. Colonies were streaked on a new YPC plate, grown for two days, and subjected to a colony lift to Zeta-Probe $\odot$ GT Blotting membranes (Biorad). After cell lysis and DNA cross-linking, the DNA was subjected to pre-hybridization and hybridization using a DIG High Prime DNA labeling and detection starter kit II (Roche) according to the manufacturer's instructions with a DIG-labeled probe of $\sim 100-200 \mathrm{bp}$ annealing in the targeted gene (for primer sequences, see Table S2). Colonies to which the probe did not bind were grown in liquid YPC media, and genomic DNA was isolated as described previously (Allers et al., 2004). The genomic DNA of several selected mutants was analyzed with PCR using primers that anneal outside of the flanking regions of the deleted gene (see Table S2), and the products formed were compared with those of the wild-type H26 strain on an agarose gel.

Strains, plasmids and primers. The strains, plasmid and primer sequences used in this study can be found in Tables S2-S4.

Motility assays of $\boldsymbol{H}$. volcanii on semisolid agar plates. Motility assays were performed using the same method as previously described (Quax et al., 2018b; Li et al., 2019). Semi solid agar plates were made in YPC medium containing $0.3 \%$ agar, $50 \mu \mathrm{g} / \mathrm{mL}$ uracil and 1 $\mathrm{mM}$ tryptophan. Fresh cells were inoculated in $5 \mathrm{~mL} C A$ medium with $50 \mu \mathrm{g} / \mathrm{mL}$ uracil and/or tryptophan when required. $10 \mu \mathrm{L}$ of the inoculum of each strain were dropped on the same semi solid agar plates. The experiment was performed at least three independent times (containing 3 biological replicates each). The motility ring formed on semi solid agar plates after cultivation at $45^{\circ} \mathrm{C}$ for 5 days were scanned, and the diameter was measured.

Transmission Electron Microscopy. Cells were grown over night at $42{ }^{\circ} \mathrm{C}$ in CA medium to an OD600 of $\sim 0.05$ and then harvested by centrifugation of 3000 $\mathrm{g}$ for $10 \mathrm{~min}$. Cells were concentrated and resuspended in CA medium with $2 \%$ (vol/vol) glutaraldehyde and $1 \%$ (vol/vol) para-formaldehyde. Cells were adsorbed to glow-discharged carboncoated grids with Formvar films for $30 \mathrm{sec}$. Samples were washed three times in distilled $\mathrm{H}_{2} \mathrm{O}$ and negatively stained with $2 \%$ (wt/vol) uranyl acetate. Cells were imaged using a Philips CM10 transmission EM coupled to a Gatan BioScan camera and the Gatan DigitalMicrograph software.

Western blotting analysis. Strains were grown under similar conditions as those for fluorescence microscopy analysis. The cells were harvested by centrifugation and concentrated to a theoretical OD of 22. Total cell lysates were separated on by SDS-PAGE (sodium dodecyl sulfate-polyacrylamide gel electrophoresis) on two $12 \%$ acrylamide gels. One gel was blotted to a PVDF (Polyvinylidene fluoride) membrane (Roche) by semi-dry Western blotting. The gels were stained with Quick Coomassie (Generon Ltd.). The membrane was subsequently incubated in blocking buffer $\left(0.2 \%\right.$ I-Block $^{\mathrm{TM}}, 0.1 \%$ Tween) (Thermo Fisher Scientific, MA, USA) at room temperature for 2 h. After 3 times washing with PBST buffer $(0.1 \mathrm{~g} / \mathrm{L}$ $\mathrm{CaCl}_{2}, \quad 0.2 \mathrm{~g} / \mathrm{L} \mathrm{KCl}, 0.2 \mathrm{~g} / \mathrm{L} \quad \mathrm{KH}_{2} \mathrm{PO}_{4}, \quad 0.1 \mathrm{~g} / \mathrm{L}$ $\mathrm{MgCl}_{2} \times 6 \mathrm{H}_{2} \mathrm{O}, 8 \mathrm{~g} / \mathrm{L} \mathrm{NaCl}, 1.15 \mathrm{~g} / \mathrm{L} \mathrm{Na} \mathrm{HPO}_{4}, \mathrm{pH} 7.4$ ), the membrane was incubated in anti-GFP antibody diluted to $1: 1,000$ in PBST buffer for $1 \mathrm{~h}$ at room temperature. After three washes in PBST, a secondary anti-rabbit antibody (from goat) coupled to HRP (horseradish peroxidase) (Thermo Fisher Scientific, MA, USA) was added to the membrane $(1: 5,000)$. Clarity ECL Western blotting substrate (Thermo Fisher Scientific) was used for visualization of the chemiluminescent signals in a ECL ChemoCam Imager (Intas, Germany).

Fluorescence Microscopy. $H$. volcanii precultures were grown in $5 \mathrm{~mL} C A$ medium overnight. The next day the cultures were diluted to a theoretical OD of 0.005 in $20 \mathrm{~mL}$ of CA medium at $42{ }^{\circ} \mathrm{C}$. After 16 hours the cultures had an OD of 0.01-0.05 and were imaged. During the last hour before observation by microscopy, $0.2 \mathrm{mM}$ tryptophan was added. Cells were pipetted on an agarose pad ( $1 \%$ agar, $18 \%$ SW) and covered with a glass slip. The cells were observed at 100x magnification in the phase contrast (PH3) mode on a Zeiss Axio Observer 2.1 Microscope equipped with a heated XL-5 2000 Incubator running VisiVIEWP software. Each experiment was repeated on at least three independent occasions resulting in the analysis of over 500 cells per strain. 
bioRxiv preprint doi: https://doi.org/10.1101/2020.04.09.033365; this version posted April 9, 2020. The copyright holder for this preprint (which was not certified by peer review) is the author/funder, who has granted bioRxiv a license to display the preprint in perpetuity. It is made available under aCC-BY-NC-ND 4.0 International license.

ArICDE form the archaeal switch complex

To track the mobility of protein foci with live imaging, $0.38 \%$ agar pads made of CA containing $1 \mathrm{mM}$ tryptophan were poured in a round DF $0.17 \mathrm{~mm}$ microscopy dish (Bioptechs). After drying, the cells were placed underneath the agar pad, and the lid was placed on the microscopy dish. Images in the PH3 and GFP modes were captured at $100 \times$ magnification every 3 minutes for 1 hour at $45^{\circ} \mathrm{C}$.

Image analysis. Microscopy images were processed using the ImageJ plugin MicrobeJ (Ducret et al., 2016). The number of foci per cell was counted, and the cells were divided over bins based on the number of cellular foci. The number of cells with the same positioning patterns was calculated as a percentage of the total. The parameters of the detection of the fluorescent foci were set to the same levels for all the proteins analyzed. Fluorescent foci movement in the time-lapse image series was characterized by time-space plots generated by the 'Surface plotter' function in ImageJ (Ducret et al., 2016). To determine if the percentage of cells with foci was significantly different between strains, an unpaired two-tailed T-test was performed on the percentages calculated for each independent experiment (minimally 3 ). Total number of analyzed cells was $>500$ per strain.

\section{Acknowledgements}

We thank Frank Braun and Phillip Nußbaum for support with experiments. The TEM is operated by the University of Freiburg, Faculty of Biology, as a partner unit within the Microscopy and Image Analysis Platform, Freiburg. This work was supported by the Deutsche Forschungsgemeinschaft (German Research Foundation) with an Emmy Nöther grant (411069969) to T.E.F.Q. and a grant within the Collaborative Research Centre SFB 1381 (403222702-SFB 1381) S-.V.A. Z.L. was supported by a CSC scholarship from the Chinese government.

\section{Authors Contribution}

T.E.F.Q. and S.-V.A. designed research. Z.L., M.R. and T.E.F.Q. performed research and interpreted data. T.E.F.Q. and S.-V.A. wrote the paper. All authors read and contributed to the manuscript.

\section{Data availability statement}

The data that supports the findings of this study are available in the supplementary material of this article

\section{Abbreviated Summary}

The bacterial-like chemotaxis system is essential for directional movement in Archaea. So far, it was unknown how the signal is transferred from the archaeal CheY to the archaellum motor to initiate motor switching. In this study we demonstrate that the proteins ArICDE represent the archaellum switch complex which is the docking point for the CheY-CheF complex and essential for archaellum filament switching.

\section{References}

Alam, M., and Oesterhelt, D. (1984) Morphology, function and isolation of halobacterial flagella. $J \mathrm{Mol}$ Biol 176: 459-75.

Albers, S.-V., and Jarrell, K.F. (2015) The archaellum: how archaea swim. Front Microbiol 6: 23.

Albers, S.-V., and Jarrell, K.F. (2018) The Archaellum: An Update on the Unique Archaeal Motility Structure. Trends Microbiol 26: 351-362.

Allers, T., Ngo, H.P., Mevarech, M., and Lloyd, R.G. (2004) Development of additional selectable markers for the halophilic archaeon Haloferax volcanii based on the leuB and trpA genes. Appl Env Microbiol 70: 943953.

Altegoer, F., and Bange, G. (2015) Undiscovered regions on the molecular landscape of flagellar assembly. Curr Opin Microbiol 28: 98-105.

Banerjee, A., Neiner, T., Tripp, P., and Albers, S.V. (2013) Insights into subunit interactions in the Sulfolobus acidocaldarius archaellum cytoplasmic complex. FEBS J 280: 6141-6149.

Barak, R., and Eisenbach, M. (1992) Correlation between phosphorylation of the chemotaxis protein CheY and its activity at the flagellar motor. Biochemistry 31: 1821-6.

Bardy, S.L., and Jarrell, K.F. (2003) Cleavage of preflagellins by an aspartic acid signal peptidase is essential for flagellation in the archaeon Methanococcus voltae. Mol Microbiol 50: 1339-47.

Beeby, M., Ferreira, J.L., Tripp, P., Albers, S.-V., and Mitchell, D.R. (2020) Propulsive nanomachines: the convergent evolution of archaella, flagella, and cilia. FEMS Microbiol Rev.

Berg, H.C., and Anderson, R.A. (1973) Bacteria swim by rotating their flagellar filaments. Nature 245: 380-2.

Bi, S., and Sourjik, V. (2018) Stimulus sensing and signal processing in bacterial chemotaxis. Curr Opin Microbiol 45: 22-29.

Brendel, J., Stoll, B., Lange, S.J., Sharma, K., Lenz, C., Stachler, A.-E., et al. (2014) A complex of Cas proteins 5,6 , and 7 is required for the biogenesis and stability of clustered regularly interspaced short palindromic repeats (crispr)-derived rnas (crrnas) in Haloferax volcanii. J Biol Chem 289: 7164-7177.

Briegel, A., Ladinsky, M.S., Oikonomou, C., Jones, C.W., Harris, M.J., Fowler, D.J., et al. (2014) Structure of bacterial cytoplasmic chemoreceptor arrays and 
bioRxiv preprint doi: https://doi.org/10.1101/2020.04.09.033365; this version posted April 9, 2020. The copyright holder for this preprint (which was not certified by peer review) is the author/funder, who has granted bioRxiv a license to display the preprint in perpetuity. It is made available under aCC-BY-NC-ND 4.0 International license.

ArICDE form the archaeal switch complex

implications for chemotactic signaling. Elife 3: e02151.

Briegel, A., Li, X., Bilwes, A.M., Hughes, K.T., Jensen, G.J., and Crane, B.R. (2012) Bacterial chemoreceptor arrays are hexagonally packed trimers of receptor dimers networked by rings of kinase and coupling proteins. Proc Natl Acad Sci 109: 3766-3771.

Briegel, A., Oikonomou, C.M., Chang, Y.-W., Kjær, A., Huang, A.N., Kim, K.W., et al. (2017) Morphology of the archaellar motor and associated cytoplasmic cone in Thermococcus kodakaraensis. EMBO Rep 18: 1660-1670.

Briegel, A., Ortega, D.R., Huang, A.N., Oikonomou, C.M., Gunsalus, R.P., and Jensen, G.J. (2015) Structural conservation of chemotaxis machinery across Archaea and Bacteria. Environ Microbiol Rep 7: 414-419.

Chaban, B., Ng, S.Y., Kanbe, M., Saltzman, I., Nimmo, G., Aizawa, S., and Jarrell, K.F. (2007) Systematic deletion analyses of the fla genes in the flagella operon identify several genes essential for proper assembly and function of flagella in the archaeon, Methanococcus maripaludis. Mol Microbiol 66: 596609.

Chaudhury, P., Does, C. van der, and Albers, S.-V. (2018) Characterization of the ATPase Flal of the motor complex of the Pyrococcus furiosus archaellum and its interactions between the ATP-binding protein FlaH. PeerJ 6: e4984.

Chaudhury, P., Neiner, T., D'Imprima, E., Banerjee, A., Reindl, S., Ghosh, A., et al. (2016) The nucleotidedependent interaction of FlaH and Flal is essential for assembly and function of the archaellum motor. Mol Microbiol 99: 674-685.

Chevance, F.F., and Hughes, K.T. (2008) Coordinating assembly of a bacterial macromolecular machine. Nat Rev Microbiol 6: 455-465.

Daum, B., Quax, T.E.F., Sachse, M., Mills, D.J., Reimann, J., Yildiz, Ö., et al. (2014) Self-assembly of the general membrane-remodeling protein PVAP into sevenfold virus-associated pyramids. Proc Natl Acad Sci U S A 111: 3829-34.

Daum, B., Vonck, J., Bellack, A., Chaudhury, P., Reichelt, R., Albers, S.-V., et al. (2017) Structure and in situ organisation of the Pyrococcus furiosus archaellum machinery. Elife 6.

Ducret, A., Quardokus, E.M., and Brun, Y. V (2016) MicrobeJ, a tool for high throughput bacterial cell detection and quantitative analysis. Nat Microbiol 1: 16077.

Erhardt, M., Namba, K., and Hughes, K.T. (2010) Bacterial nanomachines: the flagellum and type III injectisome. Cold Spring Harb Perspect Biol 2: a000299.
Ghosh, A., Hartung, S., van der Does, C., Tainer, J.A., and Albers, S.-V. (2011) Archaeal flagellar ATPase motor shows ATP-dependent hexameric assembly and activity stimulation by specific lipid binding. Biochem $J$ 437: 43-52.

Jarrell, K.F., and Albers, S. V (2012) The archaellum: an old motility structure with a new name. Trends Microbiol 20: 307-312.

Kalmokoff, M.L., and Jarrell, K.F. (1991) Cloning and sequencing of a multigene family encoding the flagellins of Methanococcus voltae. J Bacteriol 173: 7113-7125.

Kupper, J., Marwan, W., Typke, D., Grünberg, H., Uwer, U., Gluch, M., and Oesterhelt, D. (1994) The flagellar bundle of Halobacterium salinarium is inserted into a distinct polar cap structure. J Bacteriol 176: 5184-7.

Lassak, K., Neiner, T., Ghosh, A., Klingl, A., Wirth, R., and Albers, S.V. (2012) Molecular analysis of the crenarchaeal flagellum. Mol Microbiol 83: 110-124.

Li, Z., Kinosita, Y., Rodriguez-Franco, M., Nußbaum, P., Braun, F., Delpech, F., et al. (2019) Positioning of the Motility Machinery in Halophilic Archaea. MBio 10.

Parkinson, J.S., Hazelbauer, G.L., and Falke, J.J. (2015) Signaling and sensory adaptation in Escherichia coli chemoreceptors: 2015 update. Trends Microbiol 23: 257-266.

Patenge, N., Berendes, A., Engelhardt, H., Schuster, S.C., and Oesterhelt, D. (2001) The fla gene cluster is involved in the biogenesis of flagella in Halobacterium salinarum. Mol Microbiol 41: 653-663.

Paul, K., Brunstetter, D., Titen, S., and Blair, D.F. (2011) A molecular mechanism of direction switching in the flagellar motor of Escherichia coli. Proc Natl Acad Sci US A 108: 17171-6.

Pohlschroder, M., Pfeiffer, F., Schulze, S., and Abdul Halim, M.F. (2018) Archaeal cell surface biogenesis. FEMS Microbiol Rev 42: 694-717.

Porter, S.L., Wadhams, G.H., and Armitage, J.P. (2011) Signal processing in complex chemotaxis pathways. Nat Rev Microbiol 9: 153-165.

Quax, T.E.F., Albers, S.-V., and Pfeiffer, F. (2018a) Taxis in archaea. Emerg Top Life Sci 2: 535-546.

Quax, T.E.F., Altegoer, F., Rossi, F., Li, Z., RodriguezFranco, M., Kraus, F., et al. (2018b) Structure and function of the archaeal response regulator $\mathrm{CheY}$. Proc Natl Acad Sci 115: E1259-E1268.

Reindl, S., Ghosh, A., Williams, G.J., Lassak, K., Neiner, T., Henche, A.-L., et al. (2013) Insights into Flal functions in archaeal motor assembly and motility from structures, conformations, and genetics. Mol Cell 49: 1069-82. 
bioRxiv preprint doi: https://doi.org/10.1101/2020.04.09.033365; this version posted April 9, 2020. The copyright holder for this preprint (which was not certified by peer review) is the author/funder, who has granted bioRxiv a license to display the preprint in perpetuity. It is made available under aCC-BY-NC-ND 4.0 International license.

ArICDE form the archaeal switch complex

Salah Ud-Din, A.I.M., and Roujeinikova, A. (2017) Methyl-accepting chemotaxis proteins: a core sensing element in prokaryotes and archaea. Cell Mol Life Sci 74: 3293-3303.

Sarkar, M.K., Paul, K., and Blair, D. (2010) Chemotaxis signaling protein $\mathrm{CheY}$ binds to the rotor protein FliN to control the direction of flagellar rotation in Escherichia coli. Proc Natl Acad Sci 107: 9370-9375.

Schlesner, M., Miller, A., Besir, H., Aivaliotis, M., Streif, J., Scheffer, B., et al. (2012) The protein interaction network of a taxis signal transduction system in a halophilic archaeon. BMC Microbiol 12: 272.

Schlesner, M., Miller, A., Streif, S., Staudinger, W.F., Müller, J., Scheffer, B., et al. (2009) Identification of Archaea-specific chemotaxis proteins which interact with the flagellar apparatus. BMC Microbio/ 9: 56.

Sourjik, V., and Berg, H.C. (2002) Binding of the Escherichia coli response regulator CheY to its target measured in vivo by fluorescence resonance energy transfer. Proc Natl Acad Sci 99: 12669-12674.

Staudinger, W. (2008) Investigations on Flagellar Biogenesis, Motility and Signal Transduction of Halobacterium salinarum. .

Streif, S., Staudinger, W.F., Marwan, W., and Oesterhelt, D. (2008) Flagellar Rotation in the Archaeon Halobacterium salinarum Depends on ATP. J Mol Biol 384: 1-8.

Szabo, Z., Albers, S. V, and Driessen, A.J. (2006) Active-site residues in the type IV prepilin peptidase homologue PibD from the archaeon Sulfolobus solfataricus. J Bacteriol 188: 1437-1443.

Szurmant, H., and Ordal, G.W. (2004) Diversity in chemotaxis mechanisms among the bacteria and archaea. Microbiol Mol Biol Rev 68: 301-19.

Thiem, S., Kentner, D., and Sourjik, V. (2007) Positioning of chemosensory clusters in E. coli and its relation to cell division. EMBO J 26: 1615-1623.

Thomas, N.A., and Jarrell, K.F. (2001) Characterization of Flagellum Gene Families of Methanogenic Archaea and Localization of Novel Flagellum Accessory Proteins. J Bacteriol 183: 7154 7164.

Thomas, N.A., Mueller, S., Klein, A., and Jarrell, K.F. (2002) Mutants in flal and flaJ of the archaeon Methanococcus voltae are deficient in flagellum assembly. Mol Microbiol 46: 879-887.

Welch, M., Oosawa, K., Aizawa, S., and Eisenbach, M. (1993) Phosphorylation-dependent binding of a signal molecule to the flagellar switch of bacteria. Proc Natl Acad Sci U S A 90: 8787-91.

Wuichet, K., Cantwell, B.J., and Zhulin, I.B. (2010) Evolution and phyletic distribution of two-component signal transduction systems. Curr Opin Microbiol 13: 219-25.

Wuichet, K., and Zhulin, I.B. (2010) Origins and Diversification of a Complex Signal Transduction System in Prokaryotes. Sci Signal 3: ra50-ra50.

Key words: archaea, chemotaxis, archaellum, archaeal flagellum, motility, chemosensory arrays

Conflict of interest Statement: The authors declare no conflict of interest. 